\title{
An anterolateral papillary muscle rupture due to inferoposterior ischaemia
}

\author{
M. J. Schuuring (D) D. Robbers-Visser · A. H. G. Driessen · J. J. Piek
}

Published online: 22 November 2019

(c) The Author(s) 2019

An 80-year-old man with a history of atrial fibrillation developed heart failure in 3 days. Soon after admission he went into cardiogenic shock. Electrocardiography demonstrated inferoposterior ischaemia (Fig. 1a). Transthoracic echocardiography demonstrated an anterolateral papillary muscle (APM) rupture, which was confirmed by transoesophageal echocardiography (Fig. 1b). An APM rupture was unexpected because of dual supply from the left anterior descending (LAD) and left circumflex (LCX) arteries [1-4]. The aetiology may be explained by the anatomy of the coronary circulation. Urgent angiography demonstrated an occlusion of the right coronary artery (RCA) with collateral vessels to the distal circumflex coronary (LCX) artery, a moderate distal left main stenosis, and both a subtotal LCX stenosis and a significant LAD lesion with collateral vessels to the RCA. Inferoposterior ischaemia likely induced coronary steal flow from the LAD, because the LAD stenosis was less severe than the RCA and LCX stenoses. Consequently, subendocardial ischaemia of the anterior wall emerged and led to an APM rupture. Urgent mitral valve replacement and concomitant coronary artery bypass grafting were performed. The haemodynamic parameters improved postoperatively.

M. J. Schuuring $(\bowtie) \cdot$ D. Robbers-Visser · J. J. Piek Department of Cardiology, Amsterdam University Medical Centre, location AMC, Amsterdam, The Netherlands m.j.schuuring@amsterdamumc.nl

M. J. Schuuring Department of Cardiology, Haga Teaching Hospital, The Hague, The Netherlands

A. H. G. Driessen

Department of Cardiothoracic Surgery, Amsterdam

University Medical Centre, location AMC, Amsterdam, The Netherlands
Conflict of interest M.J. Schuuring, D. Robbers-Visser, A.H.G. Driessen and J.J. Piek declare that they have no competing interests.

Open Access This article is distributed under the terms of the Creative Commons Attribution 4.0 International License (http://creativecommons.org/licenses/by/4.0/), which permits unrestricted use, distribution, and reproduction in any medium, provided you give appropriate credit to the original author(s) and the source, provide a link to the Creative Commons license, and indicate if changes were made.

\section{References}

1. Voci P, Bilotta F, Caretta Q, Mercanti C, Marino B. Papillary muscle perfusion pattern. A hypothesis for ischemic papillarymuscle dysfunction. Circulation. 1995;91:1714-8.

2. Karaduman A, Balaban İ, Keskin B, Geçmen Ç, Kahveci G. A rare complication of posterior myocardial infarction: anterolateral papillary muscle rupture. Anatol J Cardiol. 2019;22:48-50.

3. Tavakoli R, Weber A, Vogt P, Brunner H-P, Pretre R, Turina M. Surgical management of acute mitral valve regurgitation due to post-infarction papillary muscle rupture. J Heart Valve Dis. 2002;11:20-5. discussion 26.

4. Nishimura RA, Schaff HV, Shub C, Gersh BJ, Edwards WD, Tajik AJ. Papillary muscle rupture complicating acute myocardial infarction: analysis of 17 patients. Am J Cardiol. 1983;51:373-7. 
Fig. 1 a Inferoposterior myocardial ischaemia. b The anterolateral papillary muscle rupture visualised on transoesophageal echocardiography
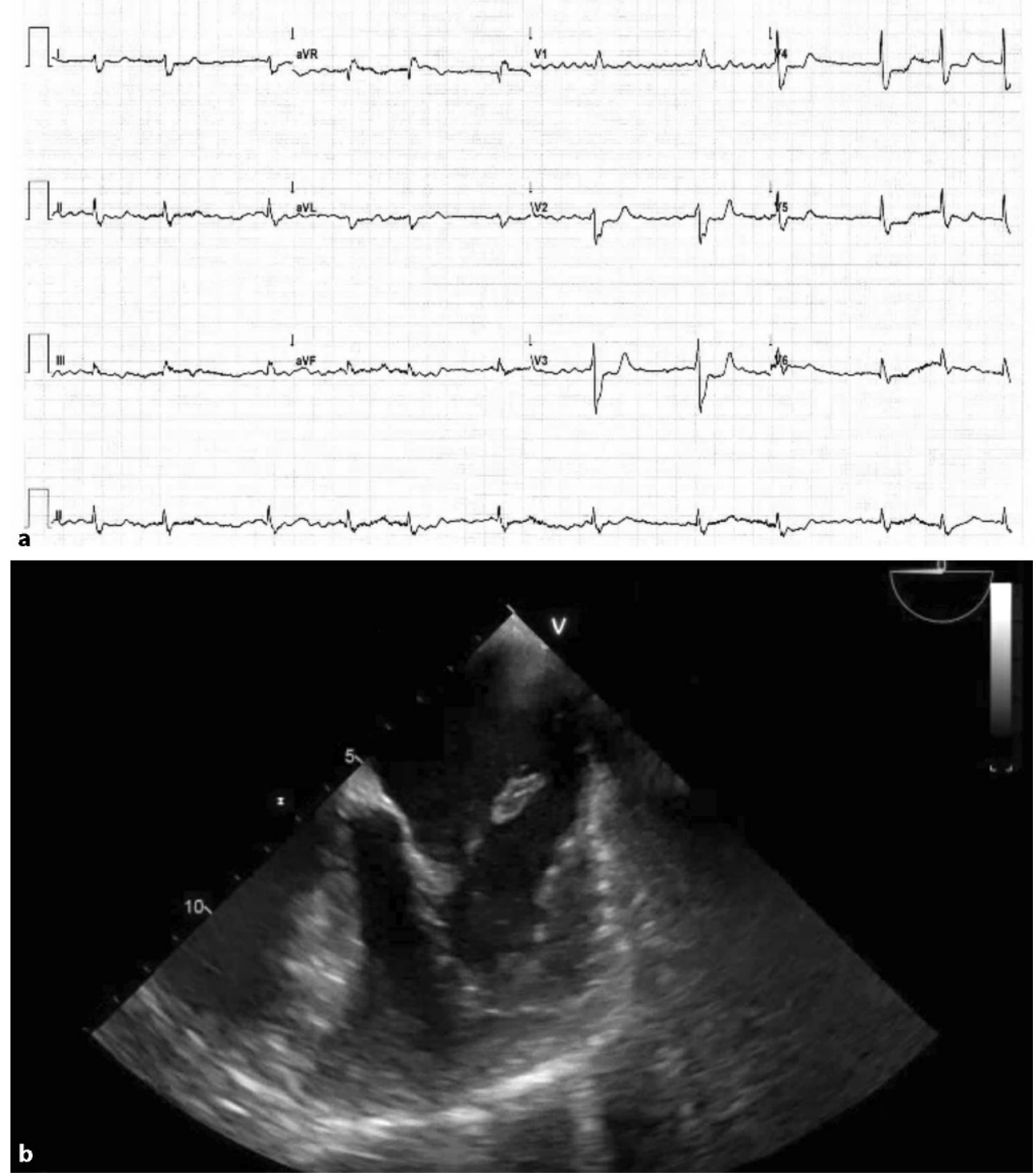